\title{
Emerging Human Resource (HR) Crisis in India: An Analysis of Critical Issues for Capacity Building
}

\author{
Dr. Puja Chhabra Sharma \\ Ansal Institute of Technolgy, Gurgaon, India \\ E.mail: pujachhabra@ hotmail.com \\ Dr. Gunmala Suri \\ University Business School, Panjab University, Chandigarh, India \\ E.mail: g_suri@yahoo.com
}

Accepted: December 26, 2011 Published: January 30, 2012

Doi:10.5296/ijld.v2i1.1324ＵRL: http://dx.doi.org/10.5296/ijld.v2i1.1324

\begin{abstract}
At a time when India is having best growth prospects in its history, we are facing a crisis of immeasurable magnitude on the HR front. A leading economist wrote that India could face full employment in the next five years. Let us wake up to this challenge and work out solutions. India has come a long way, in the education sector. Since citizens still face scarcity of opportunities, most of the teachers come to colleges and universities seeking job opportunities alone. Our work ethics is such that the best is not attracted and if they come, they can't continue. There is a definite need to develop a system, which attracts talent for faculty positions and is able to contribute its best effort towards excellence in higher education. This paper is an effort towards this direction. Current focus on education and training and enhancing capacity in that area, is perhaps the right or only answer to this. Nasscom Strategic Review indicates that out of the 3.2 million graduates that India generates every year, only about $50 \%$ of the engineers and $15-20 \%$ of other graduates are readily employable. Capacity Building' is distinct from the current models of education and training. It is focused, on-the-job training which ensures that the trainees go through real world' projects in simulated environments. The capacity building industry will need to recreate training environments for the identified skill streams in IT \& ITES. Government must invest in industrial training institutes (ITIs) and polytechnics in enabling them to be forerunners in building focused skills for the services sector expanding the scope of such institutions and opening more such institutions dedicated to the services sector. It should create a conducive environment for entrepreneurs to invest in this opportunity, by providing tax breaks, and other incentives. There is a real threat to India's
\end{abstract}


competitive position in the global business landscape, if the right things are not done. Supply-side concerns have begun to emerge. Wage inflation concerns are becoming voiced more vociferously. There is a need for all stakeholders, local, state and educational institutions, faculty and students to come together on a common platform to ensure that India continues to be able to position it- self as the knowledge capital of the world.

\section{Introduction}

Developing Countries are often starved of funds necessary for strengthening the institutions of higher education. The fear that many of these nations lag behind in scientific advancement of the developed nations makes them rush for the adoption of higher educational inputs of the developed nations, despite having limited economic resources. A developing country like ours, after more than five decades of independence could not achieve target of providing allocation of $6 \%$ of GDP to education. We have been managing with around $3 \%$ in the field of education. Merely $6 \%$ of our youth receive higher education and if we go ahead with its privatization, even then not $1 \%$ of our youth will be able to receive it (Metha, 2004).

When it comes to competing with outside world, India's higher education system leaves much to be desired. India's main competitors like China, Singapore, South Korea are investing vastly in the higher education systems. They are putting up research-based universities, which will be capable of competing with the world's best institutions. Recent London Times Higher Education Supplement ranking of the world's top 200 universities included 3 in China, 3 in Hong Kong, 3 in South Korea, one in Taiwan and only one in India. This indicates that the above countries are marching ahead to emerge as leaders in the knowledge based economies of the world (Altbach, 2005).

India has a large higher education sector. It is ranked third largest in the world after China and U.S.A. in terms of availability of scientifically and technically trained manpower in the world. It has long academic tradition where academic freedom is highly respected and it uses a universal global language, English as primary medium for higher education and research. Despite having all these advantages, India's higher education system is ill organized and highly mismanaged. Consequently, it can educate not more than $10 \%$ of its young people in higher education as compared to more than half of the younger population in the major industrialized countries.

India's colleges and universities are facing acute paucity of funds and as a result, they have become non-governable. Politicization and bureaucratization of educational system influences academic appointments, as also under investment in libraries, classrooms, etc. make it difficult to provide top quality instructions. Those in the government, and in academic institutions are not thinking creatively and are content with doing mundane things. They are well aware of the fact that the academic institutions require a careful analysis and pool of creative ideas, they seldom brother.

There is a rise in the number of part-time teachers, which has adversely affected the academic profession. These teachers are seldom accountable to either the higher authorities or the students in the academic institutions and therefore, exhibit their teaching and research performances much below the expected level. 
India is facing problem of "brain-drain". Many graduates from prestigious institutions like the Indian institutes of technology (IITS) and the Indian institutes of management (IIMS) leave the country to pursue advanced studies abroad and most of them do not return. It is estimated that about $86 \%$ of students from India in the fields of science and technology, who obtain degrees in foreign universities, do not return home immediately following the completion of their studies. This results in a great loss to a country, which is striving to compete with the economic bigwigs of the world (Altbach ,2005).

Teaching is the result of two inputs; the teaching time in terms of the efforts involved and services in the form of humane knowledge. System fails when lethargy and monotony creep into it and there is a lack of motivation to increase the present stock of knowledge through research. Both these inputs are essential if we want Indian society to progress and move over to the path of development for finding a place in the developed world.

\section{Human Resource Crisis}

India has been growing at $9 \%$ per annum for the last four years and indications are that the growth rate will be 7-9\% over the next decade. India's economy will double in the next 10 years. Per capita income is growing by $7.2 \%$ in real terms, primarily driven by economic growth and reduced growth rate of $1.6 \%$ in population over the last four years. This high growth rate has created large number of jobs to the extent that India today faces a shortage of skilled people.

India has around 500 universities and 20,000 colleges with 11 million graduates in colleges. India's enrolment rate in higher education the age group of $18-24$ years is just $11 \%$ as against the emerging market's average of $25 \%$ and an average of $50 \%$ plus in developed countries. A large number of students are studying in vernacular medium, where syllabus is totally out of touch with the demands of the job market. We have a lower number of youngsters in colleges. We are creating a large number of so-called graduates whose skill levels and capabilities are totally out of sync with what the job market requires, creating a major human resource challenge and crisis.

There is a shortage of faculty of around $30 \%$, in engineering colleges. At a time when we need people for growth, there is a shortage of faculty to help create next generation fit for marketplace.

A view of the macro-data will provide an idea of the immensity of the problem. India has about 6-6.5 crore people in the formal sector, meaning people who are on a payroll. This includes about two crore employees in government and para-government organizations across the country and the remaining in the public and private sectors.

If we double the economy in the next 10 years, we can safely assume that we need an additional six crore people in the formal sector after making room for people who retire, and for improvements in productivity. In effect, by 2028, India should have around 20 crore people employed in the formal sector as against 6-6.5 crore today. If we grow at the current rate, about 20 crore additional jobs will be created in the next 20 years. The education system is in adequate $\&$ not in a position to meet such demand.

A tragedy waits in the skilled labour area. India has a broken-down system for skill development, viz. vocational training institutions. ITI's are not producing skilled people of the required caliber. There is a tremendous shortage in India of carpenters, plumbers, electricians, 
masons, fitters, welders, drivers and other skilled people who form the backbone of any economy.

The human resources pyramid is getting inverted with more investment going into the top end. This has crated a crisis of proportions and industry is paying higher wages and is scrambling for talent. Garment industry in TamilNadu is looking to import labour from Sri Lanka and the cashew industry in Kerala is running out of labour and shifting to other places.

Let us have a look at the building industry. We would reckon that all over India, a billion square feet are currently under construction. A million square feet will provide jobs for 2,000 people. About 20 lakh people would be required to construct the billion square feet that India is currently building. Across the country, building sites are slipping behind schedule-very often by 3-6 months.

A recent report said that a major real estate company in northern India wants to import 20,000 skilled labourers from Middle East to work on their projects in India. This is at a stage when India is still at a GDP of about \$ 1.2 trillion, which may double in the next 10 years.

\section{Government Response.}

The government has recognised that there is a potential disaster in the offing, much like the disaster in the farming sector. The government is trying to open up the university and higher education systems, but is getting stung by the fact that policymakers have the mindset of the 1960 s, which is based on creating shortages.

Higher education sector needs to be accorded number one priority. India needs to ensure that every youngster in the age group of 18-24 gets the right college education. The state has to implement this mandate.

In the 2007 budget for higher education the government was unable to spend the Rs. 3,900 crore as budgeted. As against this only Rs. 1, 900 crore was spent. In 2008, a higher allocation has been made. Besides creating central universities and more IITs and IIMs, the government should come out with a plan to create a national scholarships programme giving about two million scholarships of Rs, 20,000 each, to young people across the country. This will create a demand push for higher education and ensure that students are empowered to choose the institutions they desire.

\section{Growth of Higher Education: Public Private Partnership (PPP)}

We need to have a liberal policy in place to encourage more institutions and best approach is brown field expansion rather than greenfield expansion. Positive decisions need to be taken. Higher educational institutions that have been in existence for more than 10 years be permitted to double their capacity in the next three years. In higher education, management is critical. To set up new institutions and bring in a new management team takes time and facilities are just not available. The brown field expansion will work.

The finance minister has indicated about skill development in the Union Budget and the Planning Commission has sought a national Skill Mission Group to be set up with around Rs. 35,000 crore of investment. 
The government needs to enter into a public-private partnership (PPP) on an emergency mode to bridge the skill gap. Companies in the private sector have to step in to ensure that skill development system is ramped up to a high level.

\section{Japan's Dilemma: Extreme Shortage of Engineers}

By one estimate, the digital technology industry in Japan is short by half a million engineers. Headhunters have begun poaching engineers mid career with fat signing bonuses, a predatory practice once unheard-of in Japan.

The problem is likely to worsen because Japan has one of the lowest birthrates in the world. "Japan is sitting on a demographic time bomb," said Kazuhiro Asakawa, a Professor of Business at Keio University. "An explosion is going to take place. They see it coming, but no one is doing enough about it." The shortage is causing rising anxiety about Japan's competitiveness.

China turns out some 400,000 engineers every year, hopping to usurp Japan's place one day as Asia's greatest economic power., Japan has been scrambling to entice more of its younger citizens back into the sciences and engineering. Labor experts say the belated measures are limited and unlikely to fix the problem.

In the meantime, the country has slowly begun to accept more foreign engineers, but nowhere near the number that industry needs.

While ingrained xenophobia is partly to blame, companies say Japan's language and closed corporate culture also create barriers so high that many foreign engineers simply refuse to come, even when they are recruited.

As a result companies are moving research jobs to India and Vietnam because they say it is easier than bringing non-Japanese employees here.

\section{Plight of Mumbai Varsity}

A University Grants Commissions (UGC) committee has recommended that the Centre "absorb" and convert Mumbai University into a central university because of the sorry state to which it has been reduced.

While the number of students has steadily gone up, over 200 faculty positions are lying vacant. With 600 colleges affiliated to it, the focus is more on administration than academics.

A number of academics welcomed the move. S Chapekar, a professor at the Institute of Science, said that a Varsity stood to benefit if it was controlled by the Center in terms of higher grants and better infrastructure. Central university status was a major step towards achieving excellence. There will be more flexibility and autonomy, and teaching and research which forms backbone of any institution will receive due importance.

A member of the visiting committee said that there could be state opposition to the move since Mumbai is its premier university.

About a decade ago, a similar move to turn Pune University over to the Centre never saw light of the day because of lack of political will and opposition from Maharashtra. In 2006, Punjab University faculty had appealed to the Center to make their varsity a central institution, the state refused to respond. 
Educationists in Mumbai say that the university went into decline in the early nineties and the situation turned critical in the later half of that decade after the state stopped all recruitment because of lack of funds.

Repeated letters that the university sent to the state government seeking permission to fill posts have been met with silence. Annually, the state provides salary grants of Rs. 20 crore to the university.

\section{Funding of Higher Education}

Large increases of public expenditure on higher education represents a lopsided sense of priorities. In India public money would better be spent in setting up primary schools and hospitals or on rural development and infrastructure.

We are conscious of the importance of enhancing both the quality and the size of the higher education sector in India. Anyone with a nodding acquaintance with our universities and colleges must be aware of the steep fall in the quality of teaching and research in these institutions. Decline in quality has been matched only by the relative stagnation in the number of colleges and universities-the numbers have simply not kept pace with the increase in population.

Only option is a massive increase in private funding of higher education. An overwhelmingly large number of schools in the urban sector are private schools. Except for a few medical, engineering and large number of management institutes, the private sector has hardly any presence in the higher education. There are no Harvards and Stanfords or Oxfords and Cambridges in India. Do we lack philanthropists who can set up large endowments? Or are there other reasons?

The number of Indians who are wealthy to make significant donations to educational institutions is minuscule in comparison to the numbers in the US. This cannot explain the virtual absence of any Indian university financed largely by private sector funding. The real reason for this is the animosity towards private funding of higher education in India. This is a declared policy of the left parties. Most political parties share views of the left.

It is certainly true. We paid roughly the same fees to University as our children for our postgraduate degree. This could not happen in private universities.

This would not make higher education more 'upper class' than it already is. Failure to increase number of colleges and universities means that competition to get admission is becoming tougher. The cut-off marks for the popular subjects seem to increase year after year. It is virtually impossible to gain admission into the IITs and IIMs without the benefit of coaching schools and 'study circles'.

There are exceptions. Majority of those who do well in the higher secondary go to better private schools. And the majority of these schools charge fee, which are several times the fees charged by government colleges. Since entry in these schools and perhaps subsequently into coaching schools has become more or less a prerequisite for gaining admission into the better colleges, the present system has already priced out the poorer students. 
There is little reason to believe that private funding to higher education will increase inequalities. Any increase in the number of colleges will actually reduce competition, and make it easier for students from the lower income groups to enter college.

One problem with the rapid expansion of privately funded colleges and universities is a fear that this might create a two-tier system. These institutions may have the financial resource to pay substantially higher salaries, and thus attract best teachers away from government institutions. Offsetting this is possibility that more attractive salaries may induce an increase in the supply of teachers and researchers.

Inadequate supply of teachers is one of the biggest constraints preventing a healthy expansion of the higher education. Large numbers of brightest Indians go abroad for their PhDs. Most of them do not come back. Only trickles of Indians who do not go abroad opt to enter teaching profession.

A typical response to any suggestion that teachers should be paid more is: "Large numbers of college lecturers do not even bother to take their classes". Should we pay a pittance because teachers are irresponsible or do we get such teachers because we pay such unattractive salaries?

\section{Contributions by Alumni}

Some western commentators have begun to describe India as an education superpower. Indian university graduates will soon overrun the world taking away jobs from Americans. Let's see how. India's 500 plus public universities enroll about 10 million students; private universities, may be another two million. That's still less than $10 \%$ of the potential graduate population. There is a long way to get to US college enrollment: 18 millions.

India's education budget for 2008 was around $\$ 10$ billion. States spend an equal amount and there is growing private participation. Turn to the US; Harvard University's endowment last year was $\$ 35$ billion. Yale has an endowment of $\$ 22.5$ billion. Stanford comes in third at $\$ 17.1$ billion. The top six endowment-University of Texas, Princeton, and MIT following the top three-totaled $\$ 120$ billion. Sixty-two US universities have endowments of over $\$ 1$ billion each.

In contrast, there isn't one Indian school, college, or university that has an endowment of $\$ 100$ million, let alone a billion (Orissa's Vedanta and Bihar's Nalanda are works in progress). The IITs each have an endowment of \$10-20 million now thanks to contributions from its alumni. To accept contributions rules had to be changed. IIT Kharagpur has most ambitious endowment programme, aiming to raise $\$ 200$ million-by 2020.

Tufts University's $44 \%$ growth in endowment (now at $\$ 1.2$ billion) last year was boosted by a $\$ 40$ million donation from its alumni Jonathan Tisch, now CEO of Lwews Corporation. Billionaire John Kluge, 92 a graduate of Columabia, gave $\$ 400$ million to the school last year, one of the largest ever donations in US university history. Every year there are dozens of such contributions.

Many NRIs (Non Resident Indian) give lavishly to the US Education system. In 2005, cardiologist Kiran Patel donated \$18.5 million for University of South Florida. A few years back, Milwaukee businessman Darshan Dhaliwal, who owns a chain of gas stations in the Midwest, gave $\$ 4.5$ million to University of Wisconsin, the largest private gift in its 38-year-old history. Even Indian graduates of US schools are writing cheques. Ajit Prabhu, a 
1998 graduate of Rensselaer Polytechnic, America's oldest engineering college, recently donated $\$ 2,50,000$.

US schools are relentless in reaching out to alumni through newsletters and email. In India, except for the IITs, and more recently the IIMs and IIsc, few schools and colleges have any kind of alumni outreach. When was the last time you heard from your school or college? And when did you last get in touch? Such a communication gap is unforgivable in this day and age.

\section{Creating a World Class University}

The competition to be ranked among the world's top universities is increasing. According to the latest Shanghai Jiao Tong University Ranking, the US dominates with 37 of its universities in the top 50. This is starting to change. China, is investing heavily in its universities, but there is still a long way to go before they find themselves in the top 50 .

India, as the most populous and vibrant democracy the world has ever known, the aspiration to become part of the global network of international universities that collaborate and compete can only be for the good of India \& the whole world.

What makes a university world class? As international competition of students and academics increase, this question is on the front burner for university leaders. People talk about world-class universities, but what the term means is often left undefined.

Four factors make a university world class. First, it must show a commitment to breadth and excellence in all fields of human inquiry. Uniform excellence across all fields is an ideal that no university achieves in practice, but it is always a fine ambition. One can sense universal, high ambition in great universities, with real excellence in most fields, most of the time.

World-class universities engage in cutting edge research and at the same time teaching the next generation, their students. Teaching and research are intrinsically bound, with top researchers inspiring and mentoring their students. In turn, students inspire teachers.

Most thought about world class universities centers around the production of exciting discoveries and universities' contribution to the economy and to human enrichment through the development of cultural knowledge. World-class universities produce students who go on to be leaders in all walks of life.

Great universities allow their researchers the freedom to experiment, succeed, and sometimes fail. They must be able to make grand mistakes as well as grand discoveries. It is often through making mistakes that grand discoveries are made. This implies a degree of inefficiency. It is necessary and a corollary of greatness. A university operating with a completely utilitarian mindset will forego opportunities that a more open-ended system allows.

Lastly world-class universities have permeable boundaries. This implies encouraging interdisciplinary research and teaching. It means working with private sector, fostering and encouraging international collaboration. World-class universities look outward, and think beyond conventional boundaries. Today, we educate students most of whom will go on to live and work in a range of cultures. We must equip them for this life; partly by what we teach them and partly by what other experiences we offer them. There are many challenges. Encourage groups of students from different countries to mix rather than segregate, as universities are to be real centers of international diversity. 
Universities are engaged in a global competition for talent, and need to project themselves internationally to attract the best minds. The competition at undergraduate level, US universities are offering generous scholarships as part of the attraction.

The global challenge besetting society today cannot be resolved by single university or nation working alone. These challenges include climate change and the development of sustainable sources of energy, security, religious conflict, infectious disease and the intermingling of human and animal disease, the stewardship of our natural resources and biodiversity, on land and in the sea. These and other great challenges faced by the world lend themselves to a joint approach.

There's more to this spirit of internationalism if one believes, that higher education is of great benefit to humanity through educating informed citizens and world leaders and promoting economic and cultural wealth and understanding.

Other issues with which universities grapple include intellectual property rights and, the manner in which we create sustainable universities and reduce our carbon footprint.

All these areas show importance for universities of reaching out beyond their own region or nation to embrace a global approach and in future.

Let us emphasis the universities must never forge that they are much embedded in their countries and their regions. The great universities become economic hotspots and play a huge role in their region. This is as true for Stanford University in the creation of Silicon Valley in the US as it is for Cambridge University in the creation of Silicon fen in the UK.

We are all part of where we live and, we must look to the future, managing a balance between international and local interest that is one of the main challenges universities face today.

\section{Talent Management System for Faculty Development}

A strategic perspective of human resource development management is critical for creating and sustaining human-resource-based competitive advantage. This is true of a firm, as also for educational institutions. Swami Vivekananda felt that education is a multidimensional 'man-making' process with specific purpose of achieving maximum self-realization for the person and for the optimal benefit to the society. Education should enable a person to develop cognitive, affective and psychomotor skills in accordance with inherent capability of the individual. Higher education system carries its share of the responsibility of 'man-making' along with primary and secondary education.

Quality of human resource primarily determines sustained development of a nation. This quality depends on knowledge, skills and attitudes of the human beings. Role of Higher Education is critical in development of knowledge and hence of the nation. This in turn depends on the quality of human resources in colleges and universities. Unfortunately, this vital aspect has not attracted the attention it deserves.

India has come a long way, in the education sector. Since citizens still face scarcity of opportunities, most of the teachers come to colleges and universities seeking job opportunities alone. Our work ethics is such that the best is not attracted and if they come, they can't continue. There is a definite need to develop a system, which attracts talent for faculty 
positions and is able to contribute its best effort towards the excellence of higher education. This paper is an effort towards this direction.

Talent Management System (TMS) is an effective tool for creating symbiotic

relationship between talent and the educational institutions to dramatically accelerate performance improvements. TMS can elevate talent to a visible and exalted position to which others will aspire. It can cause people to recognize special contributors in meaningful ways. TMS is a powerful magnet in demonstrating that the institution cares about talent and their joy-of-work needs.

A TMS will impact policy making of higher education system in the following manner:

- Framing a policy for identifying, attracting,keeping, and managing talent in higher education.

- Helping training of talent in Academic Staff Colleges.

- Preparing data bank of talent for specific projects/research.

- Assessing quality of research degrees like Ph. D and M. Phil.

- Weight-age of soft-skills vs. Functional skills in selection of teachers.

- Rethinking on award of $\mathrm{PhD/fellowship} \mathrm{through} \mathrm{structured} \mathrm{programmes} \mathrm{of} \mathrm{three} \mathrm{years}$ duration with one-year work experience.

- Implementing student's evaluation of teachers.

- Assigning weight-age to candidates with industry experience in selection of faculty.

- Creating a Think Tank for improving Higher Education.

- Obtaining realistic inputs for working on HRI (Human Resources Index) defined by UNO or HDI (Human Development Index).

- Enhancing student learning through mastering learning strategies.

- Improving HRD function throughout India.

\section{Conclusion}

At a time when India is having best growth prospects in its history, we are facing a crisis of immeasurable magnitude on the HR front. A leading economist wrote that India could face full employment in the next five years. Let us wake up to this challenge and work out solutions.

CK Prahaland's vision for India 15 years from now is, undoubtedly, very ambitious but not impossible to achieve. As he imagines India can be home to 30 of the fortune-100 companies. So, India can emerge as the largest pool of technically trained manpower-200 million college graduates and 500 million certified and skilled technicians anywhere in the world over this period. This can be made possible if India overhauls its education system. If education at all levels is geared towards real learning and empowerment, nothing can stop India from having the largest pool of skilled manpower servicing the global economy. Becoming a source of global innovations is easily achievable. As the professor pointed out, greatness can be accomplished if we change our mindset, have precise goals and set new standards rather than blindly adopt best practices from the west. India needs to look inwards and draw inspiration from its own genius to invent the "next practice" of economic development.

Evolving out own modernity is the biggest challenge Indians face collectively. Everyone agrees India has to work out her own trajectory of development. This has to be rooted in her cultural and social context. 
Last two decades have seen India emerging as the knowledge capital of the world. A phenomenon that started with India providing qualified talent pool of the developed economies has now assumed titanic proportions. World's largest and most prominent companies are sourcing technology, processes and engineering services from either their own captive services centers or from global and Indian-origin, third party vendors.

One of the key transformations that the world is witnessing today is in the breadth and depth of services that India is engaged in. As India inches towards a critical mass and supply-side constraints begin to surface, it is important to put in place appropriate measures to ensure that India's biggest asset, its human resource base, is leveraged to serve the global market effectively. We will have to establish path towards enhancing capacity, so that the world is not 'supply constrained.

Current focus on education and training and enhancing capacity in that area, is perhaps the right or only answer to this. The Nasscom Strategic Review indicates that out of the 3.2 million graduates that India generates every year, only about $50 \%$ of the engineers and $15-20 \%$ of other graduates are readily employable.

Capacity Building' is distinct from the current models of education and training. It is focused, on-the-job training which ensures that the trainees go through real world' projects in simulated environments. The' capacity building' industry will need to recreate training environments for the identified skill streams in IT \& ITES.

Government should re-look at education and training paradigm and help in conceptually evolving this industry. It needs to help in defining appropriate standards, benchmarks, and metrics, which ensure consistency across institutions operating in this space. This could be in the form of monitoring content, standardizing examinations, issue of certifications, etc.

Government must invest in industrial training institutes (ITIs) and polytechnics in enabling them to be forerunners in building focused skills for the services sector expanding the scope of such institutions and opening more such institutions dedicated to the services sector. It should create a conducive environment for entrepreneurs to invest in this opportunity, by providing tax breaks, and other incentives.

There is a real threat to India's competitive position in the global business landscape, if the right things are not done. Supply-side concerns have begun to emerge. Wage inflation concerns are be-coming voiced more vociferously. There is a need for all stakeholders, local, state and educational institutions, faculty and students to come together on a common platform to ensure that India continues to be able to position it- self as the knowledge capital of the world. 


\section{References}

1. Mehta,Rane(2004) Crises in Higher Education: Role Analysis of Teachers \& University System, New Delhi, Kalpaz Publication

2. Altbach. G. Philip (2005) "Higher Education in India", New Delhi. The Hindu. April 12.

3. Gore. M.S. (1994) "India Education: Structured and Process", Jaipur. Rawat Publications.

4. Reghuram, N. (2006) "Higher Education, Ugly Face of the Knowledge Economy", India Together. Vol. 5, Issue I.

5. Rani. S. (1998) "Higher Education in India: Roles and Responsibilities of Teacher", Journal of Higher Education, Vol 21. NO. 4, Autumn.

6. AICTE (2003), AICTE Management Education Review Committee Report.

7. Bowonder, B and Rao, SL (2004), "Management Education in India: Its Evolution and some Contemporary Issue", All India Management Association, November.

8. Mashelkar, RA (2004), "Seizing Opportunities to Leverage India's Potential in Education \& Innovation", in World Bank-Cll Workshop on 'Indian and the knowledge Economy: Leveraging Strengths and Opportunities', November 9.

9. Mc Kinsey (2001), "India: The Growth Imperative”, Mc Kinesey \& Company Inc., August, www.mckinsey.org. 